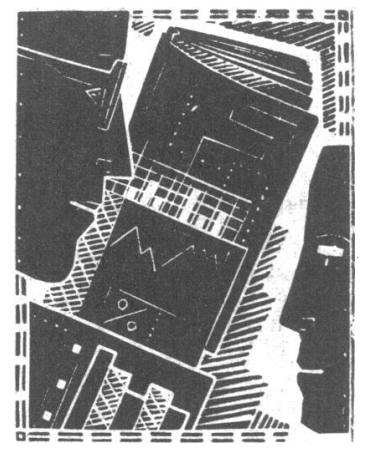

THIS WEEK . .

- In the first article Messrs fones and Collins show how a system of complexity scoring based on the recommended reimbursement scale in private practice according to the British United Provident Association's schedule of procedures allows a more acceptable and valuable assess- ment of operative workload than does estimation of caseload numbers.

- In the commissioned article Dr Batstone expands on the educational qualities of audit.

\title{
Caseload or workload? Scoring complexity of operative procedures as a means of analysing workload
}

Department of Surgery, Taunton and Somerset Hospital, Taunton TA1 5DA $S$ M Jones, FRCS, consultant surgeon

C D Collins, FRCS, consultant surgeon

Correspondence to: Mr Jones.

BrMed f 1990;301:324-5

\author{
S M Jones, C D Collins
}

\begin{abstract}
Objective-To present a more realistic assessment of surgical workload than that provided by a case count.

Design-Prospective study of all the operative procedures performed in one year, classified according to the British United Provident Association's schedule of procedures and scored by the "intermediate equivalent" value (taking the recommended fee value of an intermediate operation as 1.0 ) compared with the number of operations performed.

Setting-General surgical unit of Taunton and Somerset Hospital, comparing four consultant surgeons and their teams.

Patients-Inpatients and day patients admitted under the care of general surgeons during 1989.

Main outcome measure-Difference between the apparent workload represented by simple case counting (caseload) and the actual workload represented by calculation of the total "intermediate equivalent" value.

Results - The workload assessed in terms of intermediate equivalent values was greater than that suggested by case counting for complex operations $(12 \% v 4 \%)$, operations at the district hospital $(82 \% v$ $74 \%$, and operations performed by consultants $(53 \% v 35 \%)$ and was lower for minor operations $(20 \% v 42 \%)$, operations at the community hospitals $(18 \% v 26 \%)$, and operations performed by surgeons in training grades and clinical assistants $(47 \% v$ $66 \%$ ).

Conclusions - The use of the intermediate equivalent values as an indicator of complexity allows a more realistic assessment of the operative workload than a simple case count of the number of different operations and is recommended for comparing workload in different hospitals and departments.
\end{abstract}

\section{Introduction}

Measures of operating theatre activity and Department of Health performance indicators currently consist of the total operative procedures carried out. Though these data may be necessary in compiling management statistics, they are not useful for surgeons. Operations vary considerably in the time and skill they require, and the workload of a department, team, or individual surgeon may be misrepresented by such simple statistics. There is an urgent need for surgeons in Britain to agree on a method of weighting operative procedures according to their complexity. One readily available index of complexity that is widely used and generally accepted by surgeons is contained in the British United Provident Association (BUPA) schedule of procedures, ${ }^{1}$ which rates operative procedures according to an eight point scale from minor to complex major A and is used as a guide to fees reimbursed in private practice.

We used this rating system to audit the operative workload of a general surgical unit by calculating the relative complexity of all surgical procedures performed in one year.

\section{Patients and methods}

We studied the surgical activity of the general surgery unit at this hospital by systematic collection of clinical data on all inpatients and day patients with the medical data index computer audit system. The work of the department covers the full range of general surgery, excluding urology, and is performed by four consultants and their teams in a district general hospital and two community hospitals serving a population of about 250000 . Private general surgery is largely carried out in the local private hospital and is not included. Every operative procedure was coded according to the Office of Population Censuses and Surveys (4th revision) code (OPCS4) and also the appropriate classification in the BUPA schedule.

Intermediate equivalent values - The BUPA schedule classifies every operative procedure into one of eight groups on a scale of complexity. Taking the recommended fee value of an "intermediate" operation as the standard, we scored all the other points on the scale relative to this to give the "intermediate equivalent" value for each procedure. Using the 1989 fees limits recommended by the association for this calculation, we obtained relative values, or intermediate equivalent values (table I). These values were then applied to each procedure performed to give a complexity score. In this way an operating list of three cases comprising a sigmoid colectomy (intermediate equivalent value $2 \cdot 20$ ), cholecystectomy $(1 \cdot 75)$, and hernia repair $(1 \cdot 0)$ would give a workload value of 4.95 for a caseload of three.

\section{Results}

Study of the overall caseload of the four general surgeons for 1989 showed that for a total of 5447 discharges and deaths 4205 operations had been carried out. The total operative workload in inter- 
mediate equivalents was 4583 . Among the 4205 operations, minor procedures contributed $42 \%$ (1768) of the total operations but only a fifth (922) of the operative workload. All complex operations (complex major and major plus operations) together represented $4 \%$ (168) of the total operations but $12 \%$ (545) of the operative workload (table II). Caseload at the main district general hospital amounted to 3109 operations with an operative workload of 3763 intermediate equivalents whereas a caseload of 1096 operations was carried out at the associated peripheral hospitals with an operative workload of 820 (table III). Analysis by grade of surgeon showed that registrars or senior house officers were the named surgeon in $49 \%$ of operations (2045) but $35 \%$ of the operative workload (1602 intermediate equivalents). Similarly, clinical assistants performed $17 \%$ (696) of the operations but $12 \%$ of the operative workload (569 intermediate equivalents). Consultants were the operating surgeons or principal assistants in $35 \%$ (1464) of the operations, which comprised $53 \%$ of the operative workload (table IV).

The vascular team had a mean caseload of 818 as opposed to a mean of 1129 for the three other teams, yet the operative workload for the year was 1117 intermediate equivalents, which compared well with that of 1162 for the three other consultant teams.

\section{Discussion}

The BUPA schedule of procedures is widely used and generally accepted by surgeons. Though its origin is unclear, the scale was developed to reflect the time and skill entailed in each operative procedure and has undergone repeated modification with developments in operative procedures. Although some discrepancies are perceived within these categories, the categories do give an acceptable assessment of the clinical work entailed and allow comparison between procedures and specialties. A similar grading of operative procedures, by "hernia equivalent," was developed in the United States by Hughes $e t a l^{2}$ and used extensively in the 1970s to compare the workload of surgeons working in different practices. ${ }^{3}$

Although use of the BUPA scale as a weighting factor has previously been suggested, ${ }^{4}$ the only weighting index used in studies on workload in the United Kingdom was that developed in the North East Thames region in $1976 . .^{5}$ In a study using this index, in which operations were assigned to a major, intermediate, or minor category with a score of $2 \cdot 0,1 \cdot 0$, or 0.4 respectively, Fowkes et $a l^{6}$ found that in general surgery in England and Wales (including paediatric surgery and urology) there was an average of 1162 discharges and deaths and 999 weighted operations per consultant. In the general surgical unit in this hospital the average caseload per consultant team was 1051 operations, which approximates to an intermediate equivalent workload of 1142 , but a detailed analysis indicated distinct differences between caseload and workload. For example, in our study a case count would suggest that the vascular team carried out less work than the general surgical teams and that the contribution of peripheral hospitals to operative work-

TABLE I - Intermediate equivalent of relative values for British United Provident Association (BUPA categories of operation

\begin{tabular}{lcl}
\hline Category & $\begin{array}{c}\text { Intermediate } \\
\text { equivalent value }\end{array}$ & \multicolumn{1}{c}{ Examples } \\
\hline Minor & $0 \cdot 5$ & Gastroscopy, wedge excision of nail \\
Intermediate & $1 \cdot 0$ & Inguinal hernia, excision of breast lump \\
Major & $1 \cdot 75$ & Cholecystectomy, partial thyroidectomy \\
Major plus & $2 \cdot 20$ & Parotidectomy, colonic resection \\
Complex major D & $3 \cdot 10$ & Elective aortic aneurysm \\
Complex major C & $4 \cdot 20$ & Anterior resection of rectum \\
Complex major B & $5 \cdot 25$ & Ruptured aortic aneurysm, oesophagogastrectomy \\
Complex major A & $6 \cdot 33$ & Cardiac surgery entailing bypass \\
\hline
\end{tabular}

TABLE II - Total caseload and workload by British United Provident Association (BUPA) categories of operation

\begin{tabular}{|c|c|c|}
\hline & $\begin{array}{c}\text { Caseload }^{\star} \\
(\%)\end{array}$ & $\begin{array}{c}\text { Workload } \dagger \\
(\%)\end{array}$ \\
\hline Minor & $1768(42)$ & $922(20)$ \\
\hline Intermediate & $1428(34)$ & $1428(31)$ \\
\hline Major & $841(20)$ & $1688(37)$ \\
\hline Complex (complex major and major plus) & $168(4)$ & $545(12)$ \\
\hline Total & 4205 & 4583 \\
\hline
\end{tabular}

« Number of operations.

†Intermediate equivalent value.

TABLE III-Caseload and workload for district general hospitals and community hospitals in study

\begin{tabular}{lcc}
\hline & $\begin{array}{c}\text { Caseload } \\
(\%)\end{array}$ & $\begin{array}{c}\text { Workload } \dagger \\
(\%)\end{array}$ \\
\hline $\begin{array}{l}\text { District general hospital } \\
\text { Community hospitals }\end{array}$ & $\begin{array}{c}3109(74) \\
1096(26)\end{array}$ & $\begin{array}{r}3763(82) \\
820(18)\end{array}$ \\
\hline Total & 4205 & 4583
\end{tabular}

* Number of operations.

†Intermediate equivalent value.

TABLE IV-Caseload and workload by grade of surgeon

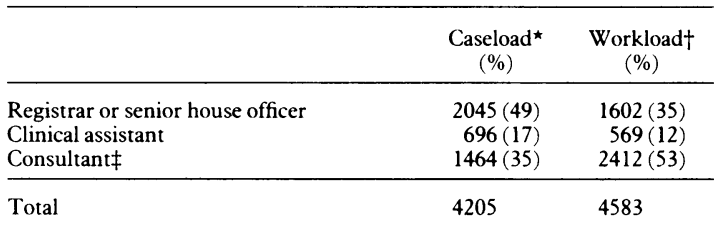

Number of operations

tIntermediate equivalent value.

¥Uurgeon or principal assistant.

load was as high as a quarter. These interpretations were considered misleading by the surgeons concerned and are shown to be inaccurate when the operative workload is expressed in intermediate equivalents.

The BUPA schedule of operations and related reimbursement rates remain the most widely used and accepted current system of relative values in the United Kingdom. We think that the intermediate equivalent workload reflects more accurately the operative workload of a surgical team than the simple addition of numbers of operations. Furthermore, it permits a relevant comparison of surgical activity in different operating theatres and hospitals.

We thank our surgical colleagues for contributing enthusiastically to this departmental surgical audit, and Miss Ruth Hoad for preparing the manuscript.

1 British United Provident Association. Schedule of procedures 1989. London: BUPA, 1989.

2 Hughes EFX, Fuches VR, Jacoby JF, Levit EM. Surgical workload in community practice. Surgery 1972;71:315-27.

3 Moore FD. Contemporary American surgery: hard data at last. $N \mathrm{Engl}$ f Med 1976;295:953-4.

4 Skinner FW, Riley D, Thomas EM. Use and abuse of performance indicators. BrMed f 1988;297:1256-9.

5 North East Thames Regional Health Authority. Major, intermediate and minor operations. London: Regional Statistical Office, 1976.

6 Fowkes FGR, Page SM, Phillips-Miles D. Surgical manpower, beds and outpu in the NHS: 1967-1977. Brf Surg 1983;70:114-6.

(Accepted 23 May 1990)

Note

One year's experience of major trauma outcome study methodology

In their article (21 July, p 156) Mr James Wardrope and others encouraged hospitals to submit data to the major trauma outcome study (UK). Such information should be sent directly to Professor D W Yates, coordinator of major trauma outcome study, North Western Injury Research Centre, Hope Hospital, Salford M6 8HD. 